\title{
A CONSTITUIÇÃO DO CAMPO DE PESQUISA EM ENSINO/APRENDIZAGEM HISTÓRICA PELA REVISTA HISTÓRIA \& ENSINO
}

\section{THE CONSTITUTION FIELD OF RESEARCH IN TEACHING/LEARNING OF HISTORY THROUGH THE HISTÓRIA \& ENSINO JOURNAL}

\author{
Márcia Elisa Teté Ramos ${ }^{1}$
}

\begin{abstract}
RESUMO: Considera a trajetória histórica da revista História \& Ensino na sua intertextualidade e contextualização. Pretende mostrar como a pesquisa no campo do ensino/aprendizagem histórica foi se configurando na revista. Realiza um levantamento dos dados em relação aos temas mais tratados nos artigos, comparando-os com aqueles circulantes em âmbito nacional, então já pesquisados por alguns autores (em especial: ZAMBONI, 2005 e COSTA; DIAS, 2007). Entende que tais temas trabalhados nos artigos estão relacionados às discussões, aos projetos, às políticas, às necessidades quanto ao ensino/aprendizagem histórica do período.
\end{abstract}

Palavras-chave: Periódico educacional. Ensino de História. Aprendizagem de História. Pesquisa em História. Formação docente.

\begin{abstract}
This article considers the historical trajectory of the História \& Ensino Journal in his intertextuality and contextualization. Aims to show how research in the field of teaching / learning history was being developed in the Journal. Make a surveying of the data in relation to the themes treated in the articles, comparing them with those circulating in national scope researched already by some authors (in particular: ZAMBONI, 2005 e COSTA; DIAS, 2007). Believes that themes worked out in Articles are related to discussions, projects, policies, needs for teaching / learning of the historical period.
\end{abstract}

Keyword: Educational Journal. Teaching of History. Learning of History. Research in History. Teacher training.

\footnotetext{
${ }^{1}$ Docente do curso de graduação em História e do curso de Mestrado de História Social da Universidade Estadual de Londrina. Doutoranda pela Universidade Federal do Paraná. Coordenadora do Laboratório de Ensino de História. Editora da revista História \& Ensino.
} 


\section{Introdução}

O Laboratório de Ensino de História da UEL (LABHIS) foi criado em 1994 pela Profa Dra Marlene Cainelli, com o intuito de aproximar a universidade da escola, no sentido de propiciar um espaço laboratorial, ou seja, de experiência, reflexão, discussão e ação, referente ao ensino/aprendizagem de história. Considerava-se o apoio à formação inicial e continuada aos professores de história do Ensino Fundamental e do Ensino Médio, incluindo os professores das séries iniciais. Baseado em tais objetivos, o LABHIS empreende eventos, elabora materiais didáticos, divulga boletins (hoje, newsletters), etc. e em 1995, publicou a primeira revista - considerando o território nacional - trazendo artigos acadêmicos sobre a temática do ensino/aprendizagem de história. O volume um da revista História \& Ensino (adiante denominada H\&E) apresentava como comissão editorial, membros do LABHIS: Gilmar Arruda, Marlene Cainelli, Mariana Josefa de Almeida (in memorian), Jozimar Paes de Almeida e William Reis Meirelles ${ }^{2}$.

Foram ao todo 22 volumes, sendo que dois volumes são "especiais": em 2002, a republicação de 18 artigos mais significativos e em 2012, com artigos inéditos dos bolsistas do Programa Institucional de Bolsa de Iniciação à Docência (PIBID). São 202 artigos, mais 26 artigos dos volumes especiais, totalizando 228 artigos.

Nosso objetivo neste artigo é perceber na trajetória histórica desta revista como o campo de pesquisa em ensino/aprendizagem da história foi se configurando, entendendo sua intertextualidade e contextualização. Para isso, agrupamos os artigos da revista considerando quatro "etapas" ou "fases", no propósito de melhor organizar a análise, e não de diferenciar

\footnotetext{
${ }^{2}$ Os volumes 2 e 3, Gilmar Arruda destaca-se como editor da revista. Do volume 5 ao volume 12 da revista, o editor foi William Reis Meirelles. Do volume 13 ao volume 15, Gilmar Arruda retorna como editor. Do volume 16 (versão eletrônica) até o momento, Márcia Elisa Teté Ramos é a editora. Na comissão editorial, além dos nomes anteriormente citados, já tivemos: André Joanilho, Cláudio Denipoti, Claudiomar dos Reis Gonçalves (in memorian), Fransico César Ferraz e José Miguel Arias Neto. Contudo, na maior parte dos volumes, a comissão editorial era composta por: Francisco César Ferraz, Gilmar Arruda, Marlene, Cainelli, e William dos Reis Meirelles.
} 
uma "etapa" da outra de forma determinista. Tomamos os assuntos mais discutidos nos artigos, bem como o referencial teórico que os fundamenta. Também consideramos a região de origem do autor, para ter uma noção da do alcance da revista.

\section{Relação autor/região:}

a) De 1995 a 2000, foram publicados 63 artigos, sendo 27 (43\%) artigos sobre ensino de história. Nesta "fase", 21 dos 63 artigos eram elaborados por professores da UEL (33\%). Dos demais, 23 artigos eram provenientes de autores ligados às instituições paranaenses como Universidade Estadual de Maringá (UEM), Universidade Estadual do Oeste do Paraná (UNIOESTE), Centro Universitário Filadélfia (UNIFIL), Universidade Estadual de Ponta Grossa (UEPG), PUC-PR e Universidade Federal do Paraná (UFPR). Considerando a região sul, soma-se um artigo de autor do Rio Grande do Sul (Universidade do Passo Fundo). De outras regiões: 3 autores eram do Rio de Janeiro, 3 eram de São Paulo, 2 da Bahia, 1 do Ceará e 1 de Goiás.

\begin{tabular}{|l|c|}
\hline Sul & $67 \%$ \\
\hline Sudeste & $18 \%$ \\
\hline Nordeste & $9 \%$ \\
\hline Centro-Oeste & $3 \%$ \\
\hline Exterior & $3 \%$ \\
\hline
\end{tabular}

Tabela 1: Relação autor/região 1995/2000

Apenas dois artigos foram escritos por professores da rede pública de ensino e um artigo foi escrito por um graduando, sendo que os demais autores tinham a formação ou de mestrado ou de doutorado. Neste momento, pensando o LABHIS como lugar de discussão entre docentes de todos os níveis de ensino e dos licenciandos, a política editorial de H\&E, embora prezasse a publicação de artigos acadêmicos, pressupunha cooptar o professor de história da rede pública de ensino, não só para a leitura, mas também para a produção de artigos. Devemos lembrar também que não 
havia o sistema de avaliação de periódicos da Coordenação de Aperfeiçoamento de Pessoal de Nível Superior (CAPES). E ainda: o campo do ensino/aprendizagem da história como pesquisa estava iniciando sua configuração. Sendo assim, mesmo os artigos sobre ensino de história, eram escritos por pesquisadores de outras áreas.

b) De 2001 a 2005 foram 54 artigos nesta "etapa", com um volume especial comemorativo com a republicação dos 18 artigos mais representativos (estes, não entraram na presente tabulação).

Outro fator importante, agora em relação ao vínculo região/autor: enquanto que no período anterior, 33\% dos artigos da revista eram publicados por professores da UEL, de 2001 a 2005 passa a ser 20\% e decresce também a porcentagem de artigos de autores paranaenses. Podemos mesmo pressupor que se os autores são de outras regiões, a revista também está atingindo um público mais amplo no que diz respeito ao território nacional. É de se supor que a prática de enviar um exemplar de H\&E para as instituições de ensino superior, públicas e privada, tenha feito com que esta ficasse mais conhecida.

\begin{tabular}{|l|c|}
\hline Sudeste & $45 \%$ \\
\hline Sul & $38 \%$ \\
\hline Nordeste & $7 \%$ \\
\hline Centro-Oeste & $7 \%$ \\
\hline Internacional & $3 \%$ \\
\hline
\end{tabular}

Tabela 2: Relação autor/região 2001/2005

c) De 2006 a 2010, dos 54 artigos, 8 são de autores ligados à Universidade Estadual de Londrina, ou seja, 15\%. Apenas dois artigos não eram específicos sobre ensino de história. Em 2010 a revista passa a ser eletrônica pelo sistema Open Journal Systems (OJS). ${ }^{3}$

Ao mesmo tempo em que as temáticas passam a ser mais entrecruzáveis, - como veremos adiante - nesta "fase" amplia-se o número de Estados na relação autor/região. Anteriormente a predominância

\footnotetext{
${ }^{3} \mathrm{Na}$ fase eletrônica, um programa que mensura o impacto de uma publicação - ver: http://www.harzing.com -, rastreou 95 citações no Google Acadêmico neste ano de 2012. Para ter uma ideia, outra revista do campo da história, qualificada pela CAPES como A2, obteve 54 citações no Google Acadêmico.
} 
de autores da região Sudeste era de São Paulo, do Sul era do Paraná, do Nordeste era da Bahia, do Centro-Oeste era de Mato Grosso do Sul. Com exceção da região Norte, autores de todos os Estados escrevem para a revista H\&E. Também ocorre um acréscimo de autores estrangeiros.

\begin{tabular}{|l|c|}
\hline Sudeste & $38 \%$ \\
\hline Sul & $31 \%$ \\
\hline Nordeste & $15 \%$ \\
\hline Centro-Oeste & $9 \%$ \\
\hline Internacional & $7 \%$ \\
\hline
\end{tabular}

Tabela 3: Relação autor/região 2006/2010

e) De 2011 a 2012 são 39 artigos incluindo os 8 artigos do volume especial de artigos do PIBID, que aqui não serão computados. Portanto, são 31 artigos, sendo 6 artigos (23\%) de autores vinculados à UEL. A revista passa a ser semestral, portanto, temos quatro volumes nesta fase (mais o volume especial do PIBID).

\begin{tabular}{|l|c|}
\hline Sudeste & $32 \%$ \\
\hline Sul & $29 \%$ \\
\hline Nordeste & $14 \%$ \\
\hline Centro-Oeste & $11 \%$ \\
\hline Internacional & $11 \%$ \\
\hline Norte & $3 \%$ \\
\hline
\end{tabular}

Tabela 4: Relação autor/região 2011/2012

Não se publica mais artigos sem que estes sejam resultados de pesquisa. Embora atualmente o campo da pesquisa em ensino/aprendizagem histórica tenha amadurecido, e por isso tenha ficado mais especializado, - o que pode ser visto no montante de artigos específicos enviados para H\&E - , a política editorial nesta "fase" da revista abre-se para temas afins: ensino de História; educação histórica; metodologias para o ensino de história; aprendizado histórico; construção do saber histórico escolar; história da disciplina de História (escolar ou acadêmica); estágio de História; ensino de História extraescolar; História da Educação; currículo de História (escolar ou acadêmico); cognição histórica; formação do professor de História; História da infância e do adolescente. 


\section{Temáticas}

\subsection{De 1995 a 2000:}

Foram publicados 63 artigos, sendo 27 (43\%) artigos sobre ensino de história. Destes 27 artigos, os temas mais tratados eram:

\begin{tabular}{|l|l|}
\hline Livro didático & $19 \%$ (5 artigos) \\
\hline Uso escolar de fontes históricas & $19 \%$ (5 artigos) \\
\hline Currículo & $11 \%$ (3 artigos) \\
\hline $\begin{array}{l}\text { Questões epistemológicas e } \\
\text { metodológicas do ensino de } \\
\text { história }\end{array}$ & $11 \%$ (3 artigos) \\
\hline História da Educação & $11 \%$ (3 artigos) \\
\hline $\begin{array}{l}\text { Formação do professor e/ou } \\
\text { formação continuada }\end{array}$ & $8 \%$ (2 artigos) \\
\hline Políticas Públicas & $8 \%$ (2 artigos) \\
\hline História da disciplina escolar & $4 \%$ (1 artigo) \\
\hline Gênero e ensino de história & $4 \%$ (1 artigo) \\
\hline Lúdico no ensino de história & $4 \%$ (1 artigo) \\
\hline Ensino de História Regional & $4 \%$ (1 artigo) \\
\hline
\end{tabular}

Quanto aos temas mais tratados, como vimos, os estudos relativos ao livro didático e ao uso escolar de fontes históricas eram enfatizados nos artigos. Como o primeiro exemplar da revista data de 1995, podemos inferir que tais problemáticas eram coerentes com as políticas públicas para educação, em especial, o Plano Nacional do Livro Didático (PNLD) e os Parâmetros Curriculares Nacionais (PCN's) ${ }^{4}$.

\footnotetext{
${ }^{4}$ Tanto o PNLD como os PCN's integravam um conjunto de políticas públicas para a educação iniciada em 1990 em diversos países, em que se procurou implantar ampla reforma educacional por intermédio de dispositivos legais, projetos e currículos, de acordo com a "Conferência Mundial de Educação para Todos", realizada em Jomtien (Tailândia) com a presença de organismos internacionais, na qual foi aprovada, como documento norteador, a "Declaração Mundial sobre Educação para Todos: satisfação das necessidades básicas de aprendizagem". No caso do Brasil, signatário da Conferência, em 1993, foi elaborado o "Plano Decenal de Educação para Todos", incorporando os resultados da Conferência de Jomtien. Ainda nesse ano, realizou-se a Conferência de Nova Delhi (Índia), através da qual se reafirmaram as definições de Jomtien, e o Brasil comprometeuse com o objetivo de garantir os conteúdos mínimos de aprendizagem até o ano de 2000, dizia-se, conforme as demandas do mundo contemporâneo. A partir do governo de Fernando Henrique Cardoso (1995-2002), o Ministério da Educação (MEC) e o Instituto Nacional de Pesquisas Educacionais (INEP) passaram a produzir dispositivos legais e instrumentos de legitimação das reformas político-
} 
Anterior a este período, na transição dos anos 80 para 90 do século passado, colocar o livro didático, em especial o de história, como "objeto de suspeição", denunciando suas supostas distorções e depreendendo o caráter "reacionário" dos conteúdos históricos que veiculava, integrava o movimento de oposição ao currículo de história associado às políticas educativas do regime militar (MUNAKATA, 1998). O ensino de história dependeria, conforme argumento corrente nesta época da chamada "redemocratização", de uma reformulação que "higienizasse" as políticas curriculares, bem como os livros didáticos, tidos como produtos da Ditadura e por isso mesmo repletos de "mentiras", "ideologias" e "falseamentos". Era imprescindível "desmistificar" determinados temas, "conscientizar" professores e alunos, incluir minorias como a mulher, o negro e o indígena. Nos debates da época sobre ensino de história, se defendia outra relação de ensino-aprendizagem diferente daquela considerada tradicional e vários escritos problematizavam o livro didático ${ }^{5}$.

Esta história considerada tradicional do livro didático, poderia ser vista também "expressão da História oficial. Esta é sintetizada no binômio: factual e de heróis. Muitas vezes, iguala-se esse tipo de História à História dita positivista" (COSTA: DIAS, 2007, p. 151)

Entretanto, nos meados do século $X X$, este movimento de "denúncia" em relação à ideologia do livro didático ou à sua linha positivista, transforma-se em um movimento de "análise", de uma forma que poderíamos entender como menos "militante", mesmo que o referencial fosse marxista, como os artigos que entendiam o livro didático pela categoria de análise "indústria cultural" ${ }^{6}$. Ao invés de apenas apontar a

educacionais. O MEC coordenou a elaboração dos PCN's do Ensino Fundamental e Médio, das Diretrizes Curriculares para o Ensino Superior e do sistema de avaliações a partir dos currículos mínimos de todos os níveis escolares, como o Sistema Nacional de Avaliação da Educação Básica, o Exame Nacional do Ensino Médio e, quanto ao ensino superior, o chamado PROVÃO (NOGUEIRA, 2001).

${ }^{5}$ Entre os quais: "As belas mentiras: a ideologia subjacente aos textos didáticos" (1981) de Maria de Lourdes Chagas Deiró Nosella, "O Livro Didático em Estudos Sociais" (1986) de Eloísa de Mattos Höfling; o caderno CEDES com o tema "O cotidiano do livro didático" (1987) e "A ideologia no livro didático" (1987) de Ana Lúcia G. de Faria.

${ }^{6}$ Por exemplo: PRIORI, A. A concepção de história nos manuais didáticos: uma releitura. História \& Ensino. v. 1, 1995. 
ideologia subjacente ao livro didático, os artigos da revista H\&E destacavam principalmente os conteúdos/personagens ausentes ${ }^{7}$ e sua linguagem conceitual e iconográfica ${ }^{8}$.

Em 1985 cria-se o Programa Nacional do Livro Didático (PNLD), para que, através de equipe técnica especializada se avaliassem os livros didáticos e disponibilizassem-nos para as escolas públicas. Os critérios de avaliação quanto aos livros didáticos de história, contemplavam as reestruturações curriculares da época, no caso, os Parâmetros Curriculares Nacionais (PCN's). Antes disso, outras políticas em relação ao livro didático aconteceram $^{9}$, porém, entre várias mudanças obtidas através do PNLD ${ }^{10}$ destacamos que, em 1996, a reprovação de um livro didático passou a se basear também em critérios relacionados aos erros conceituais, indução a erros, desatualização, preconceito ou discriminação.

Além das reestruturações curriculares e do sistema de avaliação do livro didático, condizentes com as mudanças nas políticas públicas para educação, integram o contexto o movimento de aumento das pesquisas quanto ao ensino/aprendizagem histórica na década de 90, conforme dados levantados por Ernesta Zamboni (2005). Enquanto que nos encontros ou escritos que discutiam sobre o ensino de história, nas décadas de 70/80, era comum a apresentação dos "relatos de experiências" com pouca ou

${ }^{7}$ Por exemplo: MOTA, L. T.; RODRIGUES, I. C. A questão indígena no livro didático: toda a história. História \& Ensino. v. 5, 1999; MAGALHÃES, L. H. O índio brasileiro no livro didático. História \& Ensino, v.6, 2000.

8 Por exemplo: PASTRO, S. M. G.; CONTIERO, D. T. Uma análise sobre o ensino de história e o livro didático. História \& Ensino. v. 2, 1996.

${ }^{9}$ Em 1929 com Instituto Nacional do Livro (INL); em 1938, com Comissão Nacional do Livro Didático (CNLD); em 1996, um acordo entre o Ministério da Educação (MEC) e a Agência Norte-Americana para o Desenvolvimento Internacional (Usaid) permite a criação da Comissão do Livro Técnico e Livro Didático (Colted); em 1970/71 o Instituto Nacional do Livro (INL) passa a desenvolver o Programa do Livro Didático para o Ensino Fundamental (Plidef); em 1976 com a Fundação Nacional do Material Escolar (Fename); em 1983 com Fundação de Assistência ao Estudante (FAE), que incorpora o Plidef.

10 O PNLD traz diversas mudanças, como: indicação do livro didático pelos professores; reutilização do livro, implicando a abolição do livro descartável e o aperfeiçoamento das especificações técnicas para sua produção, visando maior durabilidade e possibilitando a implantação de bancos de livros didáticos; extensão da oferta aos alunos de $1^{a}$ e $2^{a}$ séries das escolas públicas e comunitárias; fim da participação financeira dos estados, passando o controle do processo decisório para a FAE e garantindo o critério de escolha do livro pelos professores. 
nenhuma reflexão teórica, na década de 80/90, o discurso educacional era dominado pela dimensão sociopolítica e ideológica da prática pedagógica, próprio do período pós-Ditadura. Neste momento, segundo a autora, a produção da pesquisa em ensino de história, ainda incipiente quanto à análise teórica, incidiu sobre o livro didático e iniciaram-se os primeiros trabalhos sobre currículo ${ }^{11}$. O balanço elaborado pela autora quanto aos trabalhos apresentados do ENPEH e que aqui comparamos com os artigos publicados na revista, mostravam a preocupação dos pesquisadores que passava da questão da metodologia e dos recursos auxiliares de ensino (1995), das linguagens alternativas no ensino de história (1997) para a produção do conhecimento histórico em sala de aula através das fontes históricas (1999). No ENPEH de 1999 houve grande preocupação em pensar a forma de trabalhar cinema, música, fotografia, literatura e jornal nas aulas de história. Em H\&E, o emprego de fontes históricas em sala de aula será discutido de forma mais contundente, na próxima "fase".

Ainda segundo Zamboni, a História Nova foi gradualmente servindo como referencial teórico nesses trabalhos, o que seria usual em 1999/2000. Nos artigos da revista $H \& E$, notamos referência tanto à historiografia inglesa (Edward Thompson, Hobsbawm e Raymond Willians) como à historiografia francesa (Marc Ferro, Michel de Certeau, Roger Chartier e Robert Danton). Porém, não há referência ainda quanto aos autores ligados diretamente à pesquisa no ensino de história, mesmo porque o campo está começando a se constituir. Lembrando que as questões sobre ensino/aprendizagem histórica integram os programas de pós-graduação desde a década de 70 do século passado, porém, no campo da educação e não da história, e, quando no campo da história, "a discussão sobre o que e como ensinar o produto desse conhecimento foi tratada como uma questão menor, desvalorizada, menos nobre" (COSTA; DIAS, 2007, p. 147).

\footnotetext{
${ }^{11}$ Ainda: Houve a firmação do "Seminário Perspectivas do Ensino de história", em 1988 - que atenderia todos os professores da disciplina, independente do nível de ensino -, do "Encontro de Pesquisadores em Ensino de História" (ENPEH), em 1993. Houve a solicitação dessas entidades para que a Associação Nacional dos Professores de História (ANPUH) passasse a discutir a pesquisa sobre ensino/aprendizagem histórica e que a Revista Brasileira de História publicasse textos referentes a essa área.
} 


\subsection{De 2001-2005}

Dos 54 artigos deste período, 45 artigos são específicos do ensino de história, demonstrando com maior clareza a configuração identitária da revista como espaço de discussão acadêmica da área de ensino/aprendizagem histórica.

\begin{tabular}{|l|l|}
\hline $\begin{array}{l}\text { Questões epistemológicas e } \\
\text { metodológicas do ensino de } \\
\text { história }\end{array}$ & $27 \%$ (12 artigos) \\
\hline Uso escolar de fontes históricas & $11 \%$ (5 artigos) \\
\hline Livro didático & $09 \%$ (4 artigos) \\
\hline $\begin{array}{l}\text { Representações, ideias, noções } \\
\text { dos agentes escolares }\end{array}$ & $09 \%$ (4 artigos) \\
\hline $\begin{array}{l}\text { Formação do professor e/ou } \\
\text { formação continuada }\end{array}$ & $07 \%$ (3 artigos) \\
\hline Currículo & $07 \%$ (3 artigos) \\
\hline Indígena e Afro-brasileiros & $07 \%$ (3 artigos) \\
\hline Avaliação & $05 \%$ (2 artigos) \\
\hline Ensino de História Regional & $05 \%$ (2 artigos) \\
\hline Mídia & $05 \%$ (2 artigos) \\
\hline Educação ambiental & $05 \%$ (2 artigos) \\
\hline História da Educação & $02 \%$ (1 artigo) \\
\hline Políticas Públicas & $02 \%$ (1 artigo) \\
\hline História da disciplina escolar & $02 \%$ (1 artigo) \\
\hline
\end{tabular}

O que neste artigo apresentamos como "Questões epistemológicas e metodológicas do ensino de história" tem conexão com "Uso escolar de fontes históricas", mas resolvemos separar tais temáticas na tabela, entendendo que esta última refere-se à exploração de uma fonte histórica específica: filmes, música, imagens, etc. Porém, gradualmente as discussões passam a envolver as duas temáticas, em especial quando se trata do uso de fonte histórica em sala de aula. O uso escolar do documento histórico - pelo menos em H\&E - mesmo quando baseado em "relato de experiência", não condiz com descrições ou propostas de atividades didático-pedagógicas sem que haja uma reflexão teórica/metodológica.

Embora, como vimos, esta discussão já esteja atrelada à "fase" anterior, há que evidenciar que o uso escolar do documento histórico pautado em uma fundamentação epistemológica e metodológica somavam 
30\% nos artigos na revista H\&E, nesta "fase", de 2001 a 2005, somavam $38 \%$. E mais do que isso: outros temas como, por exemplo, "Currículo", "Indígena e afro-brasileiros" e "educação ambiental" envolviam a exploração de fontes históricas em sala de aula. Não existe propriamente um "atraso", ou seja, primeiro as discussões aconteceriam em âmbito nacional e posteriormente refletiriam na revista, na medida em que a configuração de um campo é um processo gradual, um movimento tensional que ocorre envolvendo políticas, currículos, pesquisas, eventos, acesso aos pesquisadores estrangeiros, defesas de dissertações e teses, etc. Há que se pontuar que os artigos da revista, neste momento, são resultado de pesquisas na área, em sua maioria, relacionados ao mestrado ou doutorado, isto é, são resultados de uma maturação acadêmica que pode implicar aproximadamente de 2 a 5 anos de estudos.

Nos artigos de H\&E neste momento, defendia-se a transposição do fazer, da criticidade do historiador para a sala de aula, através do emprego das fontes documentais ${ }^{12}$, o que ocorria nos debates da época ${ }^{13}$. Segundo Maria Auxiliadora Schmidt:

Em relação à transposição didática do procedimento histórico, o que se procura (...) é a realização em sala a de aula da própria atividade do historiador e do fazer pedagógico. Assim, o objetivo é fazer com que o conhecimento histórico seja ensinado de tal forma que dê ao aluno condições de participar do processo do fazer, do construir a História. Que o aluno possa entender que a apropriação do conhecimento é uma atividade em que se retorna ao próprio processo de elaboração do conhecimento (SCHMIDT, 1997, p. 59).

12 Por exemplo: PEREIRA NETO, A. de F. O uso de documentos escritos no ensino de história: premissas e bases para uma didática construtivista. História \& Ensino. v. 7, 2001; ROLIM, R. C. O uso do jornal para trabalhar com a noção de fato e tempo histórico. História \& Ensino. v. 8, 2002; SCHMIDT, M. A.; GARCIA, T. B. O trabalho histórico em sala de aula. História \& Ensino. v. 9, 2003; MEIRELLES, W. R. O cinema na história: o uso do filme como recurso didático. História \& Ensino. v. 10, 2004; RAMOS, M. E. T. Por uma leitura crítica da linguagem publicitária em sala de aula. História \& Ensino. v. 11, 2005.

${ }^{13}$ Duas coletâneas, "Repensando o ensino de história" (1996) e "O saber histórico em sala de aula" (1997) marcaram as discussões sobre a disciplina histórica escolar, enfocando a produção do saber histórico em sala de aula a partir dos documentos e/ou da discussão sobre a necessidade de a reestruturação curricular englobar o ensino pela pesquisa histórica. 
Schmidt explicou que a transposição didática do fazer histórico "pressupõe, entre outros procedimentos, que se trabalhe a compreensão e a explicação histórica", e implicaria "a problematização, o ensino e a construção de conceitos, a análise causal, o contexto temporal e o privilégio da exploração do documento histórico" (SCHMIDT, 1997, p. 59). Com isso, a pesquisadora definia a "transposição didática", não como facilitação, ou vulgarização da ciência de referência para a sala de aula, mas como meio de construir o conhecimento histórico através da mesma metodologia utilizada pelo historiador.

Em 1999, o "III Encontro Perspectivas do Ensino de História" abriu-se um Grupo de Trabalho denominado "Uso escolar de fontes históricas". Nesse grupo, como no de "Linguagens e ensino de história", defendia-se a noção de "transposição didática" da crítica documental. Francisco César Alves Ferraz, - membro do LABHIS e, portanto, do conselho editorial de H\&E -, neste evento entendia que "o que é novo na atual produção acadêmica e editorial sobre ensino de história e no seu debate teórico-metodológico não é adoção de fontes históricas na sala de aula", mas como é concebida sua utilização (FERRAZ, 1999, p. 682). Segundo este "novo" tipo de utilização, "o aluno é estimulado a exercitar o conhecimento da história através de suas próprias experiências com a documentação e com outros meios de informações, produzindo, portanto, seu conhecimento" (FERRAZ, p. 682283). A partir destas considerações, o autor construiu um quadro com os "procedimentos recomendáveis" para se fazer o uso escolar das fontes históricas, os quais seriam os mesmos procedimentos empreendidos pelo historiador em sua pesquisa (FERRAZ, 1999, p. 687) ${ }^{14}$.

Os PCN's declaravam sua adesão à História Nova propondo a ampliação dos temas a serem tratados em sala de aula, o que esta linha

\footnotetext{
${ }^{14}$ Os procedimentos ou problematizações da pesquisa histórica considerados pelo autor teve o documento visual como exemplo, e de forma resumida incluiriam: procedência de um documento (quem fez, quando, para quem, onde ficou, como foi sua recepção, etc.); finalidade (por que foi feita, qual a importância para a sociedade em que se originou, etc.); tema ou assunto (qual o título, se é um tema original ou seguiu modelo anterior, temáticas secundárias, como estas se articulam, etc.); estrutura técnico-formal (qual o suporte, qual a técnica e estilo, etc.) e simbolismo (se existiam simbolismos identificáveis, quais seriam, se permitem várias interpretações, etc.).
} 
historiográfica popularizou como sendo o tratamento de "novos objetos". A sugestão quanto ao estudo desses novos objetos, bem como o Construtivismo como fundamento pedagógico, implicaria em encampar os pressupostos metodológicos da História Nova, ou seja, o uso escolar do documento histórico, para que o aluno "conheça e domine procedimentos de como interrogar obras humanas do seu tempo e de outras épocas" (BRASIL, História, 1998, p. 85).

Para os PCN's, as primeiras impressões de quem teria acesso aos documentos seriam "impregnadas de idéias, valores e informações difundidas no senso comum". Estas impressões somente se sanariam pela "análise do documento nos seus detalhes", pela confrontação entre os documentos, a sua "inserção nos contextos de época", "os questionamentos quanto às suas contradições e coerências internas", que permitiriam ao estudante, "conquistar procedimentos e atitudes de pensar/refletir 1998, historicamente" (BRASIL, História, 1998, p. 86).

Nesta "fase" também se percebe nos artigos deste periódico uma preocupação em destacar o sujeito da comunidade escolar. Geralmente utilizando autores relacionados à categoria de análise "cultura escolar"15, como Forquin e Chervel, os artigos demonstram um entendimento das representações, das noções, das ideias de professores e alunos, para além do argumento de "reprodução" (COSTA; DIAS, 2007, p. 151). Os saberes dos agentes escolares seriam originais, próprios de um grupo, seriam construídos na experiência. Critica-se Chevallard ${ }^{16}$ quanto ao termo "transposição didática", como o trabalho de fabricar um objeto de ensino, ou seja, transformar o saber produzido pelo "sábio" (o cientista) em saber escolar. O problema apontado nesta concepção era o objetivo de

15 Por exemplo: SIMAN, L. M. de C. Práticas culturais e práticas escolares: aproximações e especificidades no ensino0 de história. História \& Ensino. v. 9, 2003.

${ }^{16}$ Nota-se neste ponto também que tais autores foram apropriados no Brasil a partir de 2000, mas escreveram na década de 90: FORQUIN, Jean-Claude. Escola e cultura: as bases sociais e epistemológicas do conhecimento escolar. Porto Alegre: Artes Médicas, 1993; CHERVEL, A. História das disciplinas escolares: reflexões sobre um campo de pesquisa. Teoria e Educação, Porto Alegre, n. 2, p.177-229, 1990. CHEVALLARD, Y. La transposición didáctica: Del saber sábio al saber enseñado. Buenos Aires: Aique, 1991. 
recompatibilizar o saber escolar com o saber científico de referência e/ou acadêmico para que não se tornasse obsoleto aproximando-se do senso comum. Nesse entendimento de que o saber escolar consiste no saber erudito ou acadêmico devidamente "facilitado" subentendia-se a incapacidade de a escola produzir um conhecimento válido. Para os críticos de Chevallar, o conhecimento produzido no ambiente escolar é diferente daquele produzido nas universidades, mas nem por isso inferior.

Outro referencial bastante utilizado nestes artigos diz respeito à Teoria do Currículo. Ivor Goodson, J. Gimeno Sancristán, Tomaz Tadeu da Silva e Antonio Flávio Moreira ${ }^{17}$ são autores que tratam à questão do currículo de formas diferentes, mas cujo eixo comum é a concepção de que o currículo compõe-se de conhecimentos considerados legítimos por determinado grupo social, e que, portanto, são selecionados para ser ensináveis. Prevalece a ideia de Goodson de diferenciação entre o currículo escrito e o currículo ativo. O primeiro é reconhecido como prescrito, legitimado, porque é oficial, o segundo como prática ou (re)criação em sala de aula. Goodson afirma que o currículo escrito está sujeito às atividades de negociações, (re)elaborações ou mesmo resistências dos agentes escolares, pois as práticas escolares transcendem as prescrições (GOODSON, 1991, p. 08). Vê-se que também nesta perspectiva, os agentes escolares não são vistos como sujeitos que pensam e agem conforme imposições, mas como capazes de recriar o currículo, os livros didáticos, as leis em acordo com seus próprios códigos socioculturais. Diante isso, a temática

\footnotetext{
17 Algumas obras mais utilizadas deste autores: GOODSON, Ivor. História del Currículum. La construccion social de las disciplinas escolares. Barcelona: Ediciones Pomares-Corredor, S. A.1995; GOODSON, Ivor. O currículo em mudança. Estudos na construção social do currículo. Lisboa: Porto Editora, 2001; GIMENO SACRISTÁN, J. O currículo: uma reflexão sobre a prática. 3. Ed., Porto Alegre, Artmed, 2000; SILVA, Tomaz Tadeu da. Documentos de identidade. Uma introdução às teorias do currículo. Belo Horizonte MG: Autêntica, 1999; SILVA, Tomaz Tadeu da; MOREIRA, Antonio Flávio. (Org.). Currículo, cultura e sociedade. 2 ed., São Paulo: Cortez, 1994, v. 1, p. 7-38. SILVA, Tomaz Tadeu da; MOREIRA, Antonio Flávio. (Org.). Territórios contestados. O currículo e os novos mapas políticos e culturais. Petrópolis: Vozes, 1995.
} 
"Representações, ideias, noções dos agentes escolares" passa a ser mais valorizada na $H \& E^{18}$.

\subsection{De 2006 a 2010}

São 47 artigos, em sua totalidade, relativos ao campo do ensino/aprendizagem histórica, mesmo o artigo com a temática "História da Educação".

\begin{tabular}{|l|l|}
\hline $\begin{array}{l}\text { Questões epistemológicas e } \\
\text { metodológicas do ensino de } \\
\text { história }\end{array}$ & $22 \%$ (10 artigos) \\
\hline $\begin{array}{l}\text { Formação do professor e/ou } \\
\text { formação continuada }\end{array}$ & $20 \%$ ( 9 artigos) \\
\hline Uso escolar de fontes históricas & $13 \%$ (6 artigos) \\
\hline $\begin{array}{l}\text { Representações, ideias, noções } \\
\text { dos agentes escolares }\end{array}$ & $13 \%$ (6 artigos) \\
\hline Livro didático & $11 \%$ (5 artigos) \\
\hline Indígenas e Afro-brasileiros & $04 \%$ (2 artigos) \\
\hline Patrimônio & $07 \%$ (3 artigos) \\
\hline Currículo & $02 \%$ (1 artigo) \\
\hline Ensino de História Regional & $02 \%$ (1 artigo) \\
\hline Lúdico & $02 \%$ (1 artigo) \\
\hline Educação ambiental & $02 \%$ (1 artigo) \\
\hline História da Educação & $02 \%$ (1 artigo) \\
\hline História Regional & $02 \%$ (1 artigo) \\
\hline
\end{tabular}

Um movimento já iniciado em "fase" anterior, a questão dos indígenas e dos afro-brasileiros seria enfocada não apenas na temática "Indígenas e afro-brasileiros", mas também na temática "Representações, ideias, noções dos agentes escolares", e ainda em "Livro didático". Desde o início de sua publicação, esta questão está presente: primeiro, como vimos, superando a ideia de que o livro didático traria a ideologia dominante, contudo, sem perder o referencial de que aqueles considerados "minorias" estariam "ausentes" de suas páginas; depois com os PCN's, como

${ }^{18}$ Por exemplo: CAINELLI, M. A construção dos heróis e a memória nacional entre os não letrados. História \& Ensino. v. 10, 2004; SANTOS, L. dos; SIMAN, L. M. de castro. $O$ que dizem os professores sobre o sistema de cotas para negros nas universidades públicas. História \& Ensino. v. 14, 2008. 
"pluralidade cultural", tema de "urgência social", a ser trabalhado nos "temas transversais"19 ou em especial na disciplina de história e no período em pauta como discussões antecedentes ou desdobramentos da legislação que torna obrigatório o ensino de História e Cultura Afro-Brasileira e Indígena.

A Lei de Diretrizes e Bases da Educação Nacional de 1996, no artigo 26, parágrafo 40, já determinava que "o ensino de História do Brasil levará em conta as contribuições das diferentes culturas e etnias para a formação do povo brasileiro, especialmente das matrizes indígena, africana e européia". Entretanto, a ideia de "contribuição" era denunciada por alguns artigos da revista de todas as "fases" como sendo problemática, pois, pressupunha o silêncio quanto aos conflitos, aos processos, enfim, à história da formação do país. Desde então, ocorrem em H\&E, discussões sobre exclusão, etnia, preconceito, ideias prévias dos alunos ou dos professores sobre, por exemplo, "escravidão" ou "indígena na época da colonização", etc.

Com a aprovação em 2003 da Lei no 10.639, que tornava obrigatório o ensino de História e Cultura Africana e Afro-Brasileira nas escolas de Ensino Fundamental e Médio, as discussões foram revigoradas Esta lei foi substituída em 2008 pela Lei 11.645, que incluiria também o ensino de História e Cultura Indígena. Antes, em 2004, aprovaram-se as "Diretrizes Curriculares Nacionais para a Educação das Relações Étnico-Raciais e para o Ensino de História e Cultura Afro-Brasileira e Africana". Os artigos da revista nesta "fase" dizem respeito à implementação destas leis, aos recursos e aos saberes necessários para o ensino de História e Cultura Afro-Brasileira e Indígena e a apropriação que professores e alunos fazem da legislação ou do tema na prática escolar ${ }^{20}$.

Como o momento pode ser considerado decisivo para a temática "Formação do professor e/ou formação continuada", esta passa de 7\% para $20 \%$ dos artigos em H\&E. Após as discussões travadas no começo do século

${ }^{19} \mathrm{O}$ tomo Temas Transversais integra os PCN's, se subdivide nos temas: Ética, Trabalho e Consumo, Meio Ambiente, Saúde, Orientação Sexual e Pluralidade Cultural.

${ }^{20}$ Por exemplo: AMORIM, R. M. de. O ensino para a educação das relações étnicoraciais: um olhar para o cotidiano escolar. História \& Ensino. v. 13, 2007. 
passado com as "Diretrizes Curriculares para Formação Inicial de Professores da Educação Básica, em Cursos de Nível Superior" e com as "Diretrizes Curriculares dos Cursos de História", os cursos de história em todo Brasil tiveram que reestruturar sua grade curricular, optando por licenciatura e/ou bacharelado, e por isso mesmo, enfatizando ou não a questão do ensino e do estágio de história. Da mesma forma, as discussões que diziam respeito à profissionalização do historiador - Projeto de lei do senado/n. 368, de 2009 -, direcionam-se para a questão da formação do profissional da história na articulação pesquisa e ensino, isto é, na noção de que este profissional seja ao mesmo tempo pesquisador e professor levando em conta o campo da história ${ }^{21}$. Houve nesta temática, uma maior preocupação com o ensino/aprendizagem histórica nas séries iniciais, provavelmente decorrente do fato desta articulação mencionada entre pesquisa e ensino, já que o licenciado no curso de história é formado para ministrar aulas no Ensino Fundamental e Médio, mas como pesquisador/historiador tem a possibilidade de investigar as séries iniciais ${ }^{22}$.

A temática "Representações, ideias, noções dos agentes escolares", como dissemos, refere-se ao enfoque das práticas e dos saberes do sujeito. Neste momento, os artigos passam a explorar esta questão ${ }^{23}$, por vezes com a denominação de "narrativas"24, sem desprezar a categoria de "cultura escolar" ou a Teoria do Currículo, mas considerando um campo de investigação denominado Educação Histórica ${ }^{25}$. Podemos entender que este campo se encontra em fase de configuração na última década, mas desde as décadas de 70-80 do século passado começa a ser engendrado, em especial, na Inglaterra. Atualmente, as pesquisas se localizam na Inglaterra, no

${ }^{21}$ Por exemplo: AGOSTINI, S.; PAIM, E. A. Estágio: contribuições para a formação do professor de história. História \& Ensino. v. 12, 2006; FEITOSA, M. R. O lugar da prática de ensino na formação inicial do professor de história: um estudo sobre o curso da história da UNESP, campus de Assis. História \& Ensino. v. 14, 2008.

${ }^{22}$ CAINELLI, M.; SANCHES, T. C. Saber histórico de professores nas séries iniciais: algumas perspectivas de ensino em sala de aula. História \& Ensino. v. 14, 2008.

${ }^{23}$ Por exemplo: FROTSCHER, M. Memória oficial em sala de aula: percepções de alunos do ensino médio e fundamental de Marechal Cândido Rondon - PR sobre patrimônio e bens culturais locais. História \& Ensino. v. 12, 2006.

${ }^{24}$ Por exemplo: CUNHA, A. V. C. S. da. As narrativas históricas escolares e suas matrizes de referência. História \& Ensino. v. 12, 2006.

${ }^{25}$ Por exemplo: SCHMIDT, M. A. Literacia histórica: um desafio para a educação histórica no século XXI. História \& Ensino. v. 15, 2009. 
Canadá, nos Estados Unidos e em Portugal. Nos artigos da revista, os autores tomam como referencial principalmente Isabel Barca (Portugal) e Maria Auxiliadora Schmidt (Brasil).

Embora tenhamos continuado a tabular as temáticas dos artigos, e para isso tivemos que separá-las, notamos neste período um maior entrecruzamento das mesmas. Ao mesmo tempo, os artigos de H\&E, provavelmente refletindo algo que acontecia em território brasileiro, não integravam necessariamente o campo da Educação Histórica, mas passavam a seguir linhas de orientação semelhantes as deste campo, em especial, vinculados à categoria de literacia histórica. Enfim, entrava em foco como objetivo primeiro a pesquisa sobre: "Como compreendem e o que aprendem os alunos em História?" (BARCA, 2009, p. 12). Segundo Isabel Barca, este campo de investigação busca uma "observação sistemática do real", não se centrando nos "formalismos e recursos da aula", embora estes sejam também importantes, mas nas "ideias históricas de quem aprende e ensina". Em última instância, o que se tem em meta é a qualidade do ensino de história, ou seja, as práticas em sala de aula (BARCA, 2008, p. 24). Nestes estudos em Educação Histórica, em síntese:

Os investigadores têm entrado a sua atenção nos princípios, fontes, tipologias e estratégias de aprendizagem em História, sob o pressuposto de que a intervenção na qualidade das aprendizagens exige um conhecimento sistemático das ideias históricas dos alunos, por parte de quem ensina (e exige também um conhecimento das ideias históricas destes últimos). Análise destas ideias implica um enquadramento teórico que respeite a natureza do saber histórico e que deve refletir-se, do mesmo modo, na aula de História. (BARCA, 2005, p. 15).

\subsection{Em 2011 e 2012}

\begin{tabular}{|l|l|}
\hline $\begin{array}{l}\text { Questões epistemológicas e } \\
\text { metodológicas do ensino de } \\
\text { história }\end{array}$ & $24 \%$ (10 artigos) \\
\hline Uso escolar de fontes históricas & $14 \%$ (6 artigos) \\
\hline Livro didático & $12 \%$ (5 artigos) \\
\hline História da Educação & $10 \%$ (4 artigos) \\
\hline
\end{tabular}




\begin{tabular}{|l|l|}
\hline Indígena e Afro-brasileiros & $10 \%$ (4 artigos) \\
\hline Currículo & $07 \%$ (4 artigos) \\
\hline Novas metodologias (mídias) & $07 \%$ (3 artigos) \\
\hline História da disciplina & $07 \%$ (3 artigos) \\
\hline Lúdico & $02 \%$ (1 artigo) \\
\hline Políticas públicas & $02 \%$ (1 artigo) \\
\hline Ensino de História Regional & $02 \%$ (1 artigo) \\
\hline
\end{tabular}

Embora sejam 31 artigos eferentes a esta fase, existe um maior entrecruzamento de temas, por isso a soma de 42 artigos, devido a dificuldade de estabelecer uma temática apenas.

Percebemos que do primeiro exemplar até atualmente, o livro didático nunca deixou de ter tematizado nos artigos da revista. No entanto, é sobre outro referencial que os artigos se respaldam, como a História da Leitura ou a Educação Histórica. A temática "Representações, ideias, noções dos agentes escolares" é abrangida pelas outras temáticas, pois a abordagem que enfatiza o conhecimento prévio do aluno ou do professor perpassa a maioria dos objetivos de pesquisa ${ }^{26}$. Em relação ao livro didático, por exemplo, vê-se a apropriação que alunos e professores fazem de seu conteúdo histórico, ou seja, como compreendem a história através do livro didático ${ }^{27}$. As temáticas como "Questões epistemológicas e metodológicas do ensino de história" e "Uso escolar de fontes históricas" também se apresentam nas problemáticas de pesquisa, agora devido à maior preocupação com o refinamento teórico/metodológico e algumas vezes coma adoção do conceito de literacia histórica de Peter Lee, que retomaremos posteriormente ${ }^{28}$.

Alguns autores nunca deixaram de ser citados desde o primeiro exemplar, como, entre outros: Hobsbawm, Thompson, Paulo Freire, Roger Chartier e Michel de Certeau. Permanecem desde a "fase" 2001-2005 como

\footnotetext{
${ }^{26}$ Por exemplo: AZAMBUJA, L.; SCHMIDT, M. A. "Aprendi a pensar que música também é história": a canção vai a escola: perspectivas da Educação Histórica. História \& Ensino. v. 18, n.1, 2012.

27 Exemplo da "fase" anterior: SILVA, J. R. da. Leitores e leituras em aulas de história: professores, alunos e a inventividade sobre o livro didático. História \& Ensino. v. 16, 2010.

${ }^{28}$ Por exemplo: SILVA, A. L. B. Conhecimento e aprendizagem histórica: tensões entre as perspectivas de transposição didática e da literacia histórica a partir da experiência dos professores. História \& Ensino. v. 18, 2012.
} 
referencia independente da linha teórica de investigação, autores como: Forquin, Chervel e Goodson. Em relação à pesquisa sobre ensino/aprendizagem histórica, nesta "fase" são bastante citadas: Maria Auxiliadora Schmidt, Isabel Barca, Kátia Abud e Marlene Cainelli. Desde a "fase" anterior, Jörn Rüsen servia de norte para as investigações, não apenas considerando o campo da Educação Histórica, mas principalmente nesta $^{29}$. Este referencial deve-se, segundo Aryana Costa e Margarida Dias, à ênfase em pelo menos dois pontos: 1) a aprendizagem história seria a aprendizagem da metodologia histórica, por isso sua articulação com a teoria da história; 2) os conhecimentos históricos devem servir para a experiência, para a prática dos alunos (COSTA; Dias, 2007, p. 157).

No volume especial escrito por bolsistas do PIBID da UEL, dos 8 artigos, 6 foram orientados por Marlene Cainelli no campo da história e dois por Sandra Regina Ferreira de Oliveira, no campo da pedagogia. Todos os artigos tratam do ensino de história, fundamentaram-se no campo de investigação da Educação Histórica e na proposta de aula-oficina de Isabel Barca $^{30}$, ou seja, no uso escolar de fontes históricas (História em Quadrinhos, novela, músicas, filme, reportagens, etc.) o que implica na construção do conhecimento histórico em sala de aula (conceitos substantivos e conceitos de segunda ordem). Não apenas nos artigos do número especial do PIBID, o emprego de fontes históricas para a construção do conhecimento histórico está, neste momento, vinculado ao conceito de literacia histórica.

\section{Considerações finais}

Do início da publicação de H\&E até a atualidade, percebemos que a revista se consolidou em termos de produção acadêmica, relacionada à

29 Por exemplo: SADDI, R. Didática da história como sub-disciplina da ciência histórica. História \& Ensino. v. 16, n. 1, 2010.

${ }^{30}$ Ver: BARCA, Isabel. Aula Oficina: Do Projecto à avaliação. In: BARCA, Isabel (Org.). Para uma Educação Histórica de Qualidade. Organizadora. Actas dos IV jornadas internacionais de educação histórica centro de investigação em educação (CIED). Instituto de Educação e Psicologia Universidade do Minho, 2004. 
pesquisa no campo específico do ensino/aprendizagem histórica. Os professores da rede pública de ensino não foram apartados desta produção, e nem do grupo do público-leitor, visto que muitos, participando de programas como PIBID ou PDE (Programa de Desenvolvimento Nacional) ou então participando da pós-graduação, seja em nível de especialização, de mestrado ou de doutorado, terminaram relacionando de forma mais satisfatória a questão da pesquisa e do ensino (ou teoria/prática). Assim, os autores, muitas vezes, são pesquisadores e professores.

Os artigos passam também a englobar autores de diversas regiões do Brasil, mostrando além da abrangência de circulação, o aumento de pesquisadores sobre ensino/aprendizagem história. Ao mesmo tempo, na segunda edição de 2012, houve uma revalorização de artigos de pesquisadores da UEL sob o entendimento de que, como temos uma linha de pesquisa em História e Ensino no curso de Mestrado em História Social, seria coerente que H\&E publicasse maior número da produção local.

Como campo de pesquisa, consideramos que, independente do referencial teórico e/ou de outra nomenclatura, se procura pensar o ensino/aprendizagem da história pela literacia histórica, que é categoria de explicação usada para se referir à construção de um modo específico de "ler" o mundo em acordo com a ótica da história. Seria um letramento próprio da história, um raciocínio histórico, e que, por isso mesmo, parte de procedimentos relativos à história (LEE, 2006). Isso não significa que um artigo possa diferir do que em geral se pensa na Educação Histórica. A conclusão de que nas séries iniciais, embora sejam importantes os saberes prévios dos alunos, este não tenha o nível cognitivo para a construção adequada do conhecimento histórico ${ }^{31}$. Contudo, diferentes visões são respeitadas. Existe uma divergência entre os pareceristas quanto à esta perspectiva que se embase em certa leitura de Piaget, mas prevalece o reconhecimento da competência do(a) autor(a) em se movimentar conforme seu referencial teórico.

\footnotetext{
${ }^{31}$ Por exemplo: SILVEIRA, J. A. da. Ensino de história: na busca de novas atuações, abordagens e perspectivas. História \& Ensino. n. 18, n. 02, 2012
} 
Para construir este letramento, esta compreensão do mundo e de si mesmo, em resumo, poderíamos considerar:

a) O conhecimento prévio do aluno: No domínio da Educação Histórica, seria "o conhecimento que os alunos adquirem antes ou até mesmo depois do contacto com o ensino formal. É deste modo um conhecimento muito pessoal incorporado na experiência dos alunos, envolvendo factos, crenças, emoções, perspectivas, intuições e até habilidades" (BARBOSA, 2006, p. 10). Se se considera que "os processos de aprendizado histórico não ocorrem apenas no ensino de história, mas nos mais diversos e complexos contextos da vida concreta dos aprendizes..." (RÜSEN, 2007, p. 91), subentende-se que o aluno e o professor dominam saberes históricos provindos de múltiplas esferas sociais, não necessariamente circulantes nas instituições educacionais. Por isso a pesquisa em Educação Histórica procura levantar quais são estes saberes, na medida em que um novo conhecimento se origina a partir de conhecimentos anteriores.

b) O emprego de fontes históricas em sala de aula: Para Peter Lee, a literacia histórica demanda um "compromisso de indagação" com as "marcas de identificação" da história, como "passado", "acontecimento", "evento", "causa", "mudança", etc., "o que requer um conceito de evidência" (LEE, 2006, p. 136).

Seria própria da literacia histórica "ler fontes históricas diversas, com suportes diversos, com mensagens diversas", considerando suas intenções, sua validade, bem como o cruzamento com outras fontes e mensagens (BARCA, 2004, p. 133). A análise crítica de fontes em sala de aula produz a capacidade de "transpor" tal análise para os materiais culturais com os quais o sujeito se depara na vida prática, o que dizer que a literacia histórica tende a ultrapassar os muros da escola, adquirindo propósito e/ou sentido para a vida prática. Na revista, vários artigos demonstram de forma fundamentada o emprego da fonte histórica em sala de aula, em especial, os artigos do número especial PIBID.

c) Conceitos históricos substantivos e conceitos históricos estruturais: 0 estudo/construção dos conceitos históricos ultrapassa o 
ensino de história considerado tradicional. Toda aprendizagem envolve um processo mnemônico, mas os conceitos históricos são compreendidos/construídos gradualmente, a partir da relação com os conceitos prévios que o sujeito comum adquire na sua experiência (BARCA, 2004, p. 137). Os conceitos históricos substantivos são específicos da história e estão mais vinculados às informações históricas, por exemplo: Revolução Francesa, Feudalismo, Renascimento, Guerra de Canudos, Revolução Industrial, etc. Os conceitos de segunda ordem são constitutivos da cognição histórica, isto é, dizem respeito aos fundamentos teóricos e metodológicos da história, à natureza do conhecimento histórico, entre outros: explicação histórica, fontes e evidências, consciência histórica, inferência, imaginação histórica, interpretação, narrativa, etc. Tais conceitos também são ligados à noção temporal, como mudança, permanência, evolução e transição (LEE, 2001).

A construção de uma literacia histórica ocorre na interdependência entre os conceitos substantivos e os conceitos de segunda ordem. O trabalho com fontes históricas em sala de aula propicia a construção destes conceitos, que por sua vez são construídos a partir das protonarrativas dos alunos. Em razão disto, autores viram o que o aluno pensava, por exemplo, sobre patrimônio histórico em determinado município ${ }^{32}$, ou sobre Judaísmo, Cristianismo e Islamismo ${ }^{33}$, ou ainda, sobre Escravidão (conceitos estruturais $)^{34}$. A partir desta investigação, processou-se a construção dos conhecimentos históricos estruturais como Evidência (o que pressupõe o uso do documento histórico, como arquitetura da cidade, canção, literatura); Mudança; Processo; História/Ficção, etc.

d) A questão da Empatia: Os artigos passam a falar do conceito de Empatia ou Alteridade, em especial quando se trata de ver temas como escravidão, preconceito, indígena, afro-brasileiros, etc.

32 Por exemplo: PINTO, H. Interpretação de fontes patrimoniais em educação Histórica. História \& Ensino. v. 18, n. 1, 2012.

${ }^{33}$ Exemplo já mencionado: AZAMBUJA, L.; SCHMIDT, M. A. "Aprendi a pensar que música também é história": a canção vai a escola: perspectivas da Educação Histórica. História \& Ensino. v. 18, n.1, 2012.

${ }^{34}$ CORREIA, J. S. O uso de fontes no ensino de História: o livro Úrsula de Maria Firmina dos Reis na busca pelo escravo real. História \& Ensino. v. 18, n.2, 2012. 
Peter Lee diz que poderíamos substituir a palavra "empatia" por "compreensão". Mais precisamente: "compreensão histórica", que não é um sentimento, "Embora envolva o reconhecimento de que as pessoas possuem sentimentos" (LEE, 2003, p. 20). Este pesquisador entende que a empatia histórica seria a capacidade dos alunos reconstruírem os objetivos, os valores, as crenças do Outro, aceitando que estes podem ser diferentes dos seus.

e) Natureza perspectivada do conhecimento histórico: Como dissemos, os artigos passam a ter como referencial, Jörn Rüsen e/ou autores da Educação Histórica. Contudo, mesmo que os autores se utilizam de Foucault, Beatriz Sarlo, Jacques Le Goff, Paul Veyne, Adam Schaff, Antonio Gramsci, costumam se reportar a referenciais teóricos que não podemos considerar nem "tradicionais" e nem "relativistas".

Mesmo que se entenda que a natureza do conhecimento histórico é multiperspectivada, há que se considerar que nem toda "versão histórica" pode ser aceita como válida. Segundo Isabel Barca, existe uma multiplicidade de perspectivas em história, devido aos pressupostos e contextos diferenciados de produção histórica. Porém, a Educação Histórica entende, ao contrário da abordagem relativista, que existem critérios intersubjetivos de validação das produções historiográficas, entre eles, o mais consensual seria o da "consistência da evidência". São as fontes que fornecem indícios sobre o passado, diferenciando uma abordagem ficcional da histórica (BARCA, 2001, p. 30). Peter Lee ainda nos alerta que compreender o Outro, ter empatia, nem sempre significa aceitá-lo ou compartilhar de sua cultura (LEE, 2003, p. 20).

Estes cinco itens nos fazem dimensionar a configuração de um campo de investigação em determinado periódico, que por sua vez, não está desvinculado de discussões, reflexões e estudos entabulados em âmbito nacional e mesmo internacional. 


\section{Referências bibliográficas}

ANDRÉ, M. E. D. A. de. Etnografia da Prática Escolar. Campinas: Papirus, 1995.

BARBOSA, A. F. Conhecimento tácito substantivo histórico sobre o encontro entre povos e culturas: um estudo com alunos dos $7.0^{\circ}$ e $10.0^{\circ}$ anos de escolaridade. Dissertação (Mestrado em Educação e Supervisão Pedagógica em Ensino da História) Braga: Universidade do Minho, 2006.

BARCA, I. Concepções de adolescentes sobre múltiplas explicações em História. In: BARCA, Isabel (Org.). Perspectivas em Educação Histórica. Centro de educação e Psicologia, Universidade do Minho: 2001.

Educação Histórica: uma nova área de investigação? In: ARIAS Neto, J. M. (Org.). Dez Anos em Pesquisas em Ensino de História. Londrina: Atritoart, p. 15-25. 2005.

. Investigação em Educação Histórica: fundamentos, percursos e perspectivas. In: OLIVEIRA, Margarida Maria Dias; CAINELLI, M. R.; OLIVEIRA, Almir Félix Batista. (Org.). Ensino de História: múltiplos ensinos em múltiplos espaços. Natal. RN: EDFURUN, 2008.

. Investigação em Educação Histórica em Portugal: esboço de uma análise. BARCA, I.; SCHMIDT, M. A. (Org.). Educação Histórica: investigação em Portugal e no Brasil. Braga: centro de Investigação em Educação, Universidade do Minho, 2009.

BRASIL. Secretaria de Educação Fundamental. Parâmetros curriculares nacionais: história. Brasília: MEC, SEF, 1998.

CAINELLI, M.; TUMA, M. M. História e memória na construção do pensamento histórico: uma investigação em Educação Histórica. Revista HISTEDBR On-Line, Campinas, n. 34, p 211-222, jun. 2009.

COSTA, A. L.; OLIVEIRA, M. M. D. de. O ensino de história como objeto de pesquisa no Brasil: no aniversário de 50 anos de uma área de pesquisa, notícias do que virá. Saeculum. Revista de História. n. 16, jan./jun./ 2007.

FERRAZ, F. C. A. Uma agenda alternativa para o debate sobre o uso escolar das fontes históricas. In: SCHMIDT, M. A.; CAINELLI, M. R. (Org.). III Encontro: Perspectivas do Ensino de História, Curitiba: Aos Quatro Ventos, 1999.

GOODSON, I. La construcción social del curriculum. Posibilidades y ámbitos de investigación de la historia del curriculum. Revista de Educación, n 295, p. 7-37, Madrid, 1991.

LEE, P. Progressão da compreensão dos alunos em História. In: BARCA, I. Perspectivas em educação histórica. Actas das Primeiras Jornadas Internacionais de Educação Histórica. 2001.

. "Nós fabricamos carros e eles tinham que andar a pé": compreensão das pessoas do passado. In: BARCA, I. (Org.). Educação histórica e museus. Braga: Centro de Investigação em Educação; Instituto de 
Educação e Psicologia; Universidade do Minho, 2003.

Em direção a um conceito de literacia histórica. Educar em Revista.

Especial. Dossiê: Educação Histórica. 2006.

RÜSEN, J. História viva. Teoria da História III: formas e funções do

conhecimento histórico. Trad. Estevão de Rezende Martins. Brasília: Editora Universidade de Brasília, 2007.

SCHMIDT, M. A. A formação do professor de História e o cotidiano da sala de aula. In BITTENCOURT, C. M. F. (Org.) O saber histórico em sala de aula. São Paulo: Contexto, 1997.

ZAMBONI, E. Encontros nacionais de pesquisadores de história:

perspectivas. In ARIAS NETO, J. M. (Org.). Dez anos de pesquisa em ensino de história. VI Encontro Nacional de Pesquisadores de Ensino de História.

Londrina: AtritoArt, 2005. 